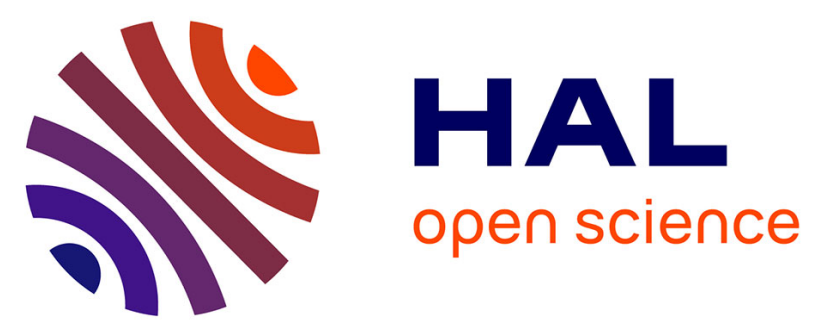

\title{
A new predictive dynamic model describing the effect of the ambient temperature and the convective heat transfer coefficient on bacterial growth
}

\author{
Hana Ben Yaghlene, Ivan Leguérinel, Moktar Hamdi, Pierre Mafart
}

\section{- To cite this version:}

Hana Ben Yaghlene, Ivan Leguérinel, Moktar Hamdi, Pierre Mafart. A new predictive dynamic model describing the effect of the ambient temperature and the convective heat transfer coefficient on bacterial growth. International Journal of Food Microbiology, 2009, 133 (1-2), pp.48-61. 10.1016/j.ijfoodmicro.2009.04.014 . hal-00553650

\section{HAL Id: hal-00553650 \\ https://hal.univ-brest.fr/hal-00553650}

Submitted on 9 Jan 2012

HAL is a multi-disciplinary open access archive for the deposit and dissemination of scientific research documents, whether they are published or not. The documents may come from teaching and research institutions in France or abroad, or from public or private research centers.
L'archive ouverte pluridisciplinaire HAL, est destinée au dépôt et à la diffusion de documents scientifiques de niveau recherche, publiés ou non, émanant des établissements d'enseignement et de recherche français ou étrangers, des laboratoires publics ou privés. 


\title{
A new predictive dynamic model describing the effect of the ambient temperature and the convective heat transfer coefficient on bacterial growth
}

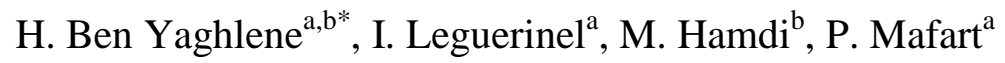 \\ ${ }^{\text {a }}$ : Université Européenne de Bretagne, EA3882, Laboratoire Universitaire de Biodiversité et Ecologie \\ Microbienne, IFR148 ScInBioS, Université de Bretagne Occidentale, 6 rue de l'université, F29334 Quimper, \\ Cedex, France \\ ${ }^{\mathrm{b}}$ : Laboratoire d'Ecologie et de Technologie Microbienne, Institut National des Sciences Appliquées et de \\ Technologie (INSAT), 2 Boulevard de la terre, B.P. 676, 1080 Tunis, Tunisie
}

"Corresponding author: LUBEM, UBO, 6 rue de l'Université, F29334, Quimper Cedex, France. Tel.: +33298 9002 27; Fax: +33298908544

E mail address: hana.benyaghlene@univ-brest.fr

\section{Abstract}

In this study, predictive microbiology and food engineering were combined in order to develop a new analytical model predicting the bacterial growth under dynamic temperature conditions. The proposed model associates a simplified primary bacterial growth model without lag, the secondary Ratkowsky "square root" model and a simplified two-parameter heat transfer model regarding an infinite slab. The model takes into consideration the product thickness, its thermal properties, the ambient air temperature, the convective heat transfer coefficient and the growth parameters of the micro organism of concern. For the validation of the overall model, five different combinations of ambient air temperature (ranging from $8{ }^{\circ} \mathrm{C}$ to $12{ }^{\circ} \mathrm{C}$ ), product thickness (ranging from $1 \mathrm{~cm}$ to $6 \mathrm{~cm}$ ) and convective heat transfer coefficient (ranging from $8 \mathrm{~W} /\left(\mathrm{m}^{2} . \mathrm{K}\right)$ to $60 \mathrm{~W} /\left(\mathrm{m}^{2} . \mathrm{K}\right)$ ) were tested during a cooling 
27 procedure. Moreover, three different ambient air temperature scenarios assuming alternated 28 cooling and heating stages, drawn from real refrigerated food processes, were tested. General 29 agreement between predicted and observed bacterial growth was obtained and less than $5 \%$ of 30 the experimental data fell outside the 95 percent confidence bands estimated by the bootstrap 31 percentile method, at all the tested conditions. Accordingly, the overall model was 32 successfully validated for isothermal and dynamic refrigeration cycles allowing for 33 temperature dynamic changes at the centre and at the surface of the product. The major 34 impact of the convective heat transfer coefficient and the product thickness on bacterial 35 growth during the product cooling was demonstrated. For instance, the time needed for the 36 same level of bacterial growth to be reached at the product's half thickness was estimated to 37 be 5 and $16.5 \mathrm{~h}$ at low and high convection level, respectively. Moreover, simulation results 38 demonstrated that the predicted bacterial growth at the air ambient temperature cannot be 39 assumed to be equivalent to the bacterial growth occurring at the product's surface or centre 40 when convection heat transfer is taken into account. Our results indicate that combining food 41 engineering and predictive microbiology models is an interesting approach providing very 42 useful tools for food safety and process optimisation.

\section{Key words:}

45 Predictive microbiology; Heat transfer; Dynamic models; Bacterial growth; Cooling; Heating. 


\section{Nomenclature}

\begin{tabular}{|ll|}
\hline$A$ & Transfer area $\left(\mathrm{m}^{2}\right)$ \\
$B i$ & Biot number \\
$E$ & Product thickness (m) \\
$f^{\prime}$ & Thermal proliferation value \\
$F o$ & Fourier number \\
$h$ & Convective heat transfer coefficient $\left(\mathrm{W} /\left(\mathrm{m}^{2} . \mathrm{K}\right)\right)$ \\
$j$ & Lag factor for reduced temperature profile \\
$k$ & Slope of the linear portion of the semi-logarithmic plot of reduced temperature $v s$ time. \\
$l$ & Characteristic dimension $(\mathrm{m})$ \\
$N$ & Microbial cell density at time $\mathrm{t}(\mathrm{CFU} / \mathrm{mL})$ \\
$N_{0}$ & Initial microbial cell density $(\mathrm{CFU} / \mathrm{mL})$ \\
$O$ & Observed microbial cell density $\left(\log { }_{10} \mathrm{CFU} / \mathrm{mL}\right)$ \\
$O D$ & Microbial optical density at time $\mathrm{t}$ \\
$O D_{0}$ & Initial microbial optical density \\
$P$ & Predicted microbial cell density $\left(\log { }_{10} \mathrm{CFU} / \mathrm{mL}\right)$ \\
$t$ & Time (s) \\
$T$ & Temperature of the product $\left({ }^{\circ} \mathrm{C}\right)$ \\
$T_{e q}$ & Equivalent temperature \\
$T_{m i n}$ & Temperature below which no microbial growth occurs $\left({ }^{\circ} \mathrm{C}\right)$ \\
$T_{o p t}$ & Temperature at which the microbial growth is optimal $\left({ }^{\circ} \mathrm{C}\right)$ \\
$T_{0}$ & Initial product temperature $\left({ }^{\circ} \mathrm{C}\right)$ \\
$T_{\infty}$ & Ambient temperature $\left({ }^{\circ} \mathrm{C}\right)$ \\
$x$ & Distance from the centre $(\mathrm{m})$ \\
$x_{\text {max }}$ & Half-thickness for an infinite slab $(\mathrm{m})$ \\
$\alpha$ & Thermal diffusivity of the product $\left(\mathrm{m}^{2} / \mathrm{s}\right)$ \\
$\Gamma$ & Overall gamma function \\
$\gamma$ & Thermal gamma function \\
$\lambda$ & Thermal conductivity of the product $(\mathrm{W} /(\mathrm{m} . \mathrm{K}))$ \\
$\mu$ & Specific microbial growth rate $\left(\mathrm{h}^{-1}\right)$ \\
$\mu_{\text {opt }}$ & Optimal specific microbial growth rate $\left(\mathrm{h}^{-1}\right)$ \\
\hline
\end{tabular}




\section{Introduction}

50 Predictive food microbiology involves knowledge of microbial growth responses to environmental factors expressed in quantitative terms by mathematical equations (models) (McMeekin et al., 1997). It is generally agreed that the most important environmental factor that affects bacterial growth in food is temperature. This factor is constantly changing during processing, storage and distribution of food products (Fujikawa et al., 2004). At the same time, control organizations propose stringent requirements regarding monitoring of the internal temperature of products being processed. For instance, according to the United States Department of Agriculture, the allowable growth of Clostridium perfringens during the cooling of certain meat and poultry products should be limited to $1 \log$ (U.S.D.A, 1999). In the case of cured products, the guidelines recommend that products' internal temperature

60 should be reduced from $54.4{ }^{\circ} \mathrm{C}$ to $26.6{ }^{\circ} \mathrm{C}$ in less than $5 \mathrm{~h}$, and from $26.6{ }^{\circ} \mathrm{C}$ to $7.2{ }^{\circ} \mathrm{C}$ in the next $10 \mathrm{~h}$ (15 h total cooling time).

Predictive microbiology is a useful tool for assessing and controlling food safety particularly when models are able to cope with dynamic conditions such as changing temperatures. Numerous published models, reported in Table 1, have dealt with the prediction of bacterial growth under dynamic temperature conditions. Generally, these works were based on predictive models corresponding to isothermal bacterial growths which were modified in order to consider the effect of temperature changes. These studies primarily aimed at assessing the feasibility of predicting the bacterial growth at changing temperature. Indeed, predicting bacterial growth under dynamic conditions has been shown to be possible via the 70 dynamic transformation of existing static models. According to the authors of the cited studies 71 (Table 1), the models' predictions agreed well with experimental results after temperature changes. 
Nevertheless, the considered scenarios of changing temperatures within bacterial models were various. In some cases, typical temperature profiles were considered either by the use of hypothetical ones or by the adoption of real temperature scenarios recorded while the studied products had been processed. In other cases, temperature profiles were simulated from heat transfer models. Mathematical models that integrate effectively heat transfer phenomena and dynamic bacterial growth relationships are scarce (Amezquita et al., 2005; de Jong et al., 2005; Zwietering and Hasting, 1997). Armitage (1997) derived the temperature histories for the deep leg and leg surface of a lamb carcass by using finite element models for dealing with regular shapes. Temperature function integration technique (TFI) was applied to the calculated temperature histories of five different cooling processes to simulate Escherichia coli growth on the leg surface of each carcass during aging. TFI technique was previously introduced by Gill and Harrison (1985). Data related to the growth of six strains of E. coli isolated from commercially packed livers were fitted according to the Ratkowsky model (Ratkowsky et al., 1982) linking the growth rate to temperature. Total growth was obtained by summation of partial growth calculated within sequential 3.75-min periods from the growth rate for the average temperature within each period. Estimated bacterial growth during offals cooling (cooling profiles were directly recorded on several offals being chilled) agreed well with observed data with E. coli. Bellara et al. (2000) experimentally validated bacterial growth modelling involving a heat transfer model of temperature fluctuations within a solid object. From data related to E. coli W3110 growth in agar, a model was set up describing bacterial growth as a function of temperature. This was then used in conjunction with a finite difference heat transfer model describing temperature change in a cylinder in order to calculate the bacterial growth that occurs in agar gel inside a cylindrical glass vessel under conduction cooling. Excellent agreement was found between model simulations and experimental data. Alavi et al. (2001) determined the growth characteristics of Listeria 
monocytogenes in sterilized whole milk. The parameter values of the Baranyi dynamic growth model (Baranyi et al., 1995) were determined. Finite element software, ANSYS, was implemented to determine temperature distributions in milk cartons subject to a time-varying ambient temperature profile. The space-time-temperature data were input to the Baranyi dynamic growth model, to predict the microbial population density distribution and the average population density in the milk carton. Amezquita et al. (2005) developed a computer simulation scheme to analyze heat transfer phenomena and temperature-dependent $C$. perfringens growth during cooling of cooked boneless cured ham. The temperature history of ham was predicted from a finite element heat diffusion model. For $C$. perfringens growth, a dynamic model was developed from the Baranyi's nonautonomous differential equation (Baranyi and Roberts, 1994). The bacterium's growth model was integrated into the computer program taking predicted temperature histories as input values. Validation of the model predictions considered three different time-temperature cooling histories from $54.4{ }^{\circ} \mathrm{C}$ to 7.2 ${ }^{\circ} \mathrm{C}$ of the geometrical centre of a large cooked boneless ham. In a further work (Corradini et al., 2006), the same data were fitted with the ad hoc empirical models in order to define the three parameters temperature dependence of the modified version of the logistic primary model. The continuous rate equation was solved incrementally by a numerical procedure implemented in general purpose software. In both Amezquita et al. (2005) and Corradini et al. (2006) works, predicted $C$. perfringens growth curves obtained from dynamic modelling showed good agreement with observed results for the tested cooling scenarios. The integrated modelling approach for predicting microbial behaviour during processing was reviewed by Lebert and Lebert (2006).

Combination of predictive microbiology and food engineering allows both the assessment of a process in relation to risk and its optimisation (Mafart, 2005). In spite of all the advances made in modelling microbial growth, proposing and improving new overall models which 
combine predictive microbiology and heat transfer phenomena is an obvious necessity. The

124 more simple the proposed models and the more realistic the considered conditions are, the easiest is their implementation to food processes.

126 In the present study, we aimed to develop a new analytical model combining bacterial growth

127 prediction and food engineering. Our goal was for the overall model to be simple and robust,

128 with minimum involved parameters, and to integrate the process conditions. The proposed

129 model is the association of three equations: a simplified primary model consisting of a simple

130 exponential growth equation without lag time, the Ratkowsky "square root" model linking the

131 specific growth rate to temperature (Ratkowsky et al., 1982), and a simplified two-parameter

132 heat transfer model regarding an infinite slab. While classical models assume that ambient

133 temperature is immediately reached at the growth medium, this work takes into account, not

134 only the air temperature, but also the thickness of the medium, its thermal properties and the 135 convective heat transfer coefficient. In addition, the proposed model may be easily 136 implemented to various micro organisms having known growth parameters.

\section{2. Development of the model}

\section{$138 \quad$ 2.1. Heat transfer modelling}

139 All cooling processes for solid materials exhibit similar behaviour. After an initial 'lag', the 140 reduced temperature at the thermal centre of the food item decreases exponentially. The linear 141 portion of the cooling curve (obtained by plotting, on semi-logarithmic axes, the reduced

142 temperature $\left(T_{\infty}-T\right) /\left(T_{\infty}-T_{0}\right)$ versus time (Becker and Fricke, 2004), see Fig. A1 in the 143 appendix) can typically be described by the simplified linear asymptotic form of the general 144 heat transfer model, valid for Fourier number $F o \geq 0.2$ with $F o=\alpha \cdot t / l^{2}$ where $\alpha$ is thermal 145 diffusivity of the product, $l$ is the characteristic dimension of the product, $T$ is the local 146 temperature of the product at the time $t, T_{0}$ is the initial temperature of the product, $T_{\infty}$ is the 
147 cooling medium temperature (pulsed air). Consequently, the heating or cooling kinetic is 148 expressed as follows:

$$
T=T_{\infty}\left(1-j e^{-k t}\right)+T_{0} j e^{-k t}
$$

150 Where $j$ is the lag factor and $k$ is the slope of the linear portion of the semi-logarithmic plot of

151 reduced temperature $v s$ time. The value of the parameter $k$ depends upon the product shape, $l$, $152 \alpha$ and the Biot number $B i=h l / \lambda$, where $h$ is the convective heat transfer coefficient between

153 the product surface area and the ambient air and $\lambda$ is the thermal conductivity of the product.

154 A low Biot number $(B i<0.1)$ indicates that the internal resistance to heat transfer is 155 negligible, and thus, the temperature within the object is uniform at any given instant in time 156 while the external thermal resistance can be neglected for $B i>40$ (Mafart, 1997).

157 The governing differential equation for infinite slab is given as follows with the initial 158 (uniform distribution of temperature) and boundary condition (surface convection):

$$
\frac{\partial T}{\partial t}=\alpha \frac{\partial^{2} T}{\partial x^{2}}
$$

where $x$ is distance from the centre. For initial condition of uniform temperature and boundary conditions of central symmetry and convective heat transfer at the surface, solution for Eq. (2) is supplied by the infinite series given by Carslaw and Jaeger (1986) (see Eq. (20) in the appendix). It is a general knowledge that use of the first term of this series would be enough

164 when the Fourier number is greater than 0.2 since the temperature change after that certain 165 time would be linear (Becker and Fricke, 2004; Bimbenet et al., 2002; Caro-Corrales et al., 2002; Dincer, 1996; Erdogdu, 2005). As long as the thermal diffusivity is constant, this first

167 term approach may be easily used to determine the temperature change with Eq. (1) and with 168 the known heat transfer coefficient value:

$169 k=\varphi^{2} \cdot \alpha / l^{2}$ at any given position in the infinite slab where $\varphi$ is the first root of the following 170 equation: 


$$
\cot \varphi=\frac{\varphi}{B i}
$$

172 At the half thickness of the infinite slab,

$$
j=\frac{2 \sin \varphi}{\varphi+\sin \varphi \cos \varphi}
$$

174 At the surface of the infinite slab,

$$
j=\frac{2 \sin \varphi \cos \varphi}{\varphi+\sin \varphi \cos \varphi}
$$

176 With respect to the cooling/heating of the product during the initial 'lag' period $\left(F_{O}<0.2\right)$, we

177 assumed a straight linear link between $T_{0}$ and temperature at time corresponding to $F_{O}=0.2$.

\subsection{Bacterial growth modelling}

179 As a primary model, a simple exponential growth without lag time was assumed:

180

$$
N=N_{0} e^{\mu t}
$$

181 Where $N$ is the cell number at time $t, N_{0}$ is the initial cell number and $\mu$ the specific bacterial 182 growth rate at time $t$.

183 The gamma function corresponds to a comparison between the growth rate of microbial cells 184 growing at given environmental conditions and the optimum growth rate that would be 185 measured at optimal conditions (Zwietering et al., 1992):

$$
\Gamma=\frac{\mu}{\mu_{o p t}}
$$

187 In the framework of standard calculations aiming to compare processes to each others, a

188 simplified gamma function depending only on temperature can be derived from the "square 189 root" model of Ratkowsky et al. (1982) modified by Zwietering et al. (1992)

$$
\gamma(T)=\left(\frac{T-T_{\min }}{T_{o p t}-T_{\min }}\right)^{2}
$$


191 Where $T_{\min }$ is the temperature below which no microbial growth occurs and $T_{\text {opt }}$ is the

192 temperature at which the microbial growth is optimal.

193 If a process has to be intrinsically assessed regardless of the characteristics of the foodstuff, a

194 partial proliferation value may be involved. If the local temperature at which the bacteria are 195 growing is the single considered factor, Mafart (2005) defined a "thermal proliferation value" 196 as:

$$
f^{\prime}=\int_{0}^{t} \gamma(T) d t
$$

198 This value has the dimension of a time and corresponds to a time-temperature cycle that would yield the same proliferation ratio than a growth of $f^{\prime}$ units of time at the optimal and constant temperature (Mafart, 2005).

The original differential form of equation (6) is:

$$
\frac{1}{N} \frac{d(N)}{d t}=\mu(t)=\mu_{o p t} \gamma[T(t)]
$$

the solution of which yields:

$$
\frac{N}{N_{0}}=\exp \left[\mu_{o p t} \int_{0}^{t}\left(\frac{T-T_{\min }}{T_{o p t}-T_{\min }}\right)^{2} d t\right]
$$

205 This model can be easily combined with heat transfer models permitting the obtainment of an analytic solution yielding the overall model. Note that, even for complex foodstuff shapes, an analytic solution of the model is possible, provided that thermal parameters of equation (1) $(j$ 208 and $k$ ) can be empirically determined from a temperature registration and a linear regression 209 of reduced temperature.

210 The concept of thermal proliferation value may be usefully completed by that of equivalent 211 temperature, which corresponds to the constant temperature that would yield the same 212 proliferation during the duration of a thermal cycle. A cooling/heating process can then be 
213 characterised and be compared with others by its duration and its equivalent temperature 214 (Mafart, 2005).

$$
\gamma\left(T_{e q}\right) t=f^{\prime}
$$

216 where time is expressed in hours. The combination of this last equation with Eq. (7) yields:

$$
T_{e q}=T_{\min }+\left(T_{o p t}-T_{\min }\right) \sqrt{\frac{f^{\prime}}{t}}
$$

\subsection{Overall model}

219 The overall model developed in the present study aims to consider the convective heat transfer coefficient and the temperature of the ambient medium when predicting bacterial growth under dynamic conditions of temperature.

222 Combining Eqs. (1) and (7) the obtained time-dependent $\gamma(T)$ function is employed in Eq. (8) in order to express, by integration, $f^{\prime}$ as a function of $t$ :

$$
f^{\prime}(T)=\frac{k\left(T_{\infty}-T_{\min }\right)^{2} t+2 j\left(T_{\infty}-T_{\min }\right)\left(T_{0}-T_{\infty}\right)\left(1-e^{-k t}\right)+\frac{j^{2}}{2}\left(T_{0}-T_{\infty}\right)^{2}\left(1-e^{-2 k t}\right)}{k\left(T_{o p t}-T_{\min }\right)^{2}}
$$

225 The substitution of $f^{\prime}$ in Eq. (13) by its above-cited expression enables the calculation of the 226 equivalent temperature as follows:

$$
T_{e q}=T_{\min }+\sqrt{\frac{k\left(T_{\infty}-T_{\min }\right)^{2} t+2 j\left(T_{\infty}-T_{\min }\right)\left(T_{0}-T_{\infty}\right)\left(1-e^{-k t}\right)+\frac{j^{2}}{2}\left(T_{0}-T_{\infty}\right)^{2}\left(1-e^{-2 k t}\right)}{k t}}
$$

228 The implementation of the Eq. (10) to $T_{e q}$ of the thermal process yields:

$$
\frac{N}{N_{0}}=\exp \left[\mu_{o p t}\left(\frac{T_{e q}-T_{\min }}{T_{o p t}-T_{\min }}\right)^{2} t\right]
$$

230 The overall mathematical model corresponds to the association of these two last equations.

231 The determination of the $j$ value at the centre (Eq. (4a)) or at the surface (Eq. (4b)) of an 232 infinite slab allows the calculation of the corresponding $T_{e q}$ values. The parameter $k$ is 
233 determined from Eq. (3) at any given position in the product and with $B i$ which includes the 234 convective heat transfer coefficient $h$ that will be changed in the experimental validation of 235 the overall model.

\section{Materials and methods}

\subsection{Micro-organism and inoculum preparation}

239 E. coli SOR 201 (isolated from cheese), provided by SOREDAB Laboratory (France), was 240 stored at $-80{ }^{\circ} \mathrm{C}$ in nutrient broth supplemented with $50 \%$ glycerol. The inoculum was 241 prepared by subculturing the bacterial strain in $100 \mathrm{~mL}$ of nutrient broth (tryptone $10 \mathrm{~g} / \mathrm{L}$, 242 meat extract $5 \mathrm{~g} / \mathrm{L}$ and sodium chloride $5 \mathrm{~g} / \mathrm{L}$. $\mathrm{pH} 7.2 \pm 0.2)$ at $37{ }^{\circ} \mathrm{C}$ on a rotary shaker $(100$ $243 \mathrm{rpm})$, subsequently for $8 \mathrm{~h}$ and $16 \mathrm{~h}$.

244 3.2. Experimental setup for the model validation at constant air temperature and changing convective heat transfer coefficient

\subsubsection{Growth measurement}

Growth curves were determined by the measurement of absorbance changes with a 248 spectrophotometer (Milton Roy, Spectronic 301) at $600 \mathrm{~nm}$ wavelength. Absorbance was 249 measured with sterile nutrient broth as a blank. Samples were filled in glass "growth flasks" specially designed for the measurement of the absorbance of the content without sampling. A calibration experiment was done to determine the correlation between viable counts and absorbance data in nutrient broth permitting the estimation of the bacterial concentrations 253 from absorbance values. Samples were incubated at $30{ }^{\circ} \mathrm{C}$ in a shaking water bath and 254 bacteria were grown until stationary phase. The optical density was periodically measured and 255 one $\mathrm{mL}$ was simultaneously removed from the solution to be analyzed by the plate count 256 method. The experimental dataset was fitted with the exponential model proposed by Juarez 257 Tomas et al. (2002) to fit the calibration equation which can be written as follows: 


$$
\operatorname{LnN}=a(O D)^{b}
$$

259 Where $N$ is the bacterial concentration, $O D$ is the corresponding optical density (600 nm) 260 measured at time $t$ and $a$ and $b$ are empirical parameters.

261 Fig. 1 depicts the experimental data and the calibration curve relating $O D$ to viable counts.

262 Estimates of parameters $a$ and $b$ were respectively assessed to 22.8 [22.6 .. 22.9] and 0.090 $263[0.087 \ldots 0.093]\left(R^{2}=0.999\right.$ and $\left.M S E=0.009\right)$.

264 Francois et al. (2005) demonstrated that a temperature of $4{ }^{\circ} \mathrm{C}$ had no significant statistical 265 effect on the linear calibration curve compared to optimal conditions $\left(T 30^{\circ} \mathrm{C}, \mathrm{pH} 7,4\right.$ and $a_{w}$ 0.995) in BHI medium. Consequently, we didn't perform the calibration experiment at other temperatures than $30{ }^{\circ} \mathrm{C}$ (the initial product temperature at all the experiments).

\subsubsection{Simulation design}

269 Five combinations of thickness of an infinite slab, convective heat transfer coefficient and 270 chilling temperature were input (Fig. 2) for the calculation of thermal parameters $j$ and $k$. A 271 simulated growth curve related to each combination was then calculated from Eqs. (14) and 272 (15). An $h$ value of $8 \mathrm{~W} /\left(\mathrm{m}^{2} . \mathrm{K}\right)$ corresponds to the absence of fan (particularly in unventilated zones or in equipment inside which heat is transferred by natural convection) while an $h$ value 274 of $60 \mathrm{~W} /\left(\mathrm{m}^{2} . \mathrm{K}\right)$ corresponds to a strong air fan (in the case of forced convection). Moreover, 275 according to Kondjoyan (2006), average heat transfer coefficient values $\left(\mathrm{W} /\left(\mathrm{m}^{2} . \mathrm{K}\right)\right)$ 276 calculated under different air velocity $\left(0.2-5.0 \mathrm{~m} \mathrm{~s}^{-1}\right)$ and free-stream turbulence intensity 277 conditions $(5-40 \%)$ ranged from 1.3 to 42.0 for a circular cylinder and from 2.3 to 60.0 for 278 meat products (Beef carcass, pork hindquarter and lamb carcass (loin)). Furthermore, Ben 279 Amara et al. (2004) studied the effect of various factors (air velocity, position, air-product 280 temperature difference) on the transfers during cooling with a low air velocity $(<0.2 \mathrm{~m} / \mathrm{s})$, of 281 an in-line stack of spheres and measured $h$ values ranging from 8 to $19 \mathrm{~W} /\left(\mathrm{m}^{2} . \mathrm{K}\right)$ for air 282 velocity varying from 0.03 to $0.19 \mathrm{~m} \mathrm{~s}^{-1}$. 


\subsubsection{Conditions of growth for the validation of the model}

284 Corresponding to each combination of slab thickness and convective heat transfer coefficient, cooling profiles and bacterial growth were simulated at the centre and at the surface of an infinite slab shaped product. The product thermal diffusivity and thermal conductivity values input in the calculations were assumed to be equal to those of water determined at $25{ }^{\circ} \mathrm{C}$, i.e. $1.43 .10^{-7} \mathrm{~m}^{2} / \mathrm{s}$ and $0.6 \mathrm{~W} /(\mathrm{m} . \mathrm{K})$ respectively.

289 Furthermore, input $\mu_{o p t}, T_{\min }$ and $T_{\text {opt }}$ values of $E$. coli SOR 201 were respectively equal to $2.66 \mathrm{~h}^{-1}, 3.28{ }^{\circ} \mathrm{C}$ and $42.03{ }^{\circ} \mathrm{C}$ in nutrient broth. These values were estimated from forty six growth kinetics conducted at 11 constant temperatures ranging from $10{ }^{\circ} \mathrm{C}$ to $46{ }^{\circ} \mathrm{C}$.

292 Experimental datasets were fitted and growth curve parameters (maximum growth rate $\left(\mu_{\max }\right)$, 293 lag time, initial and maximum population densities) were estimated from the primary growth 294 model of Baranyi and Roberts (1994). The obtained $\mu_{\max }$ values were fitted with the 295 secondary cardinal model (Rosso et al., 1995) in order to estimate the optimal growth rate and the cardinal temperatures of E. coli SOR 201 (see Fig. A2 in the appendix). In order to validate the overall mathematical model developed in the present work, experiments were conducted under a changing temperature program which corresponds to the simulated cooling profiles of the surface or the centre of the product. All the prepared material was pre-chilled/heated to the initial temperature $\left(30^{\circ} \mathrm{C}\right)$. Subculture was diluted to provide an 301 inoculation level ranging from $10^{6}$ to $10^{7} \mathrm{CFU} / \mathrm{mL}$ at the starting of the test. Samples were 302 filled in glass "growth flasks" allowing the measurement of the absorbance of the content, 303 during the experiment, without sampling. Their shaking was guaranteed by a magnetic 304 shaking table. Samples were instantly incubated and periodically removed so as to measure optical densities (at $600 \mathrm{~nm}$ ) in the course of the experiment. Experiments were carried out in triplicate. The chilling was monitored with a refrigerated and heating circulator (FP40-HE, Julabo Labortechnik GmbH, Germany) allowing a temperature stability of $\pm 0.01{ }^{\circ} \mathrm{C}$. 

constant convective heat transfer coefficient

310 For a further validation of the model, more complicated temperature scenarios were tested

311 assuming alternated cooling and heating stages. Moreover, an inoculation level ranging from

$31210^{3}$ to $10^{4} \mathrm{CFU} / \mathrm{mL}$ was used in order to consider more realistic bacterial concentrations

313 encountered in food industry processes.

314 Three different ambient air temperature scenarios, drawn from real refrigerated food 315 processes, were tested (cf. Table 2).

316 Corresponding to each air temperature scenario, temperature profiles and bacterial growth 317 were simulated at the centre and at the surface of an infinite slab shaped product. At all the 318 tested temperature scenarios, the initial product temperature, the product thickness and the 319 convective heat transfer coefficient were respectively equal to $15{ }^{\circ} \mathrm{C}, 0.12 \mathrm{~m}$ and $8 \mathrm{~W} /\left(\mathrm{m}^{2} . \mathrm{K}\right)$. Input $\mu_{o p t}, T_{\min }$ and $T_{\text {opt }}$ values of $E$. coli SOR 201 are mentioned above. Typical beef meat thermal diffusivity and thermal conductivity values, respectively equal to $1.25 .10^{-7} \mathrm{~m}^{2} / \mathrm{s}$ and $0.42 \mathrm{~W} /(\mathrm{m} . \mathrm{K})$, were input in the calculations.

Experiments were conducted under thermal programs which corresponded to the simulated 324 temperature profiles of the surface or the centre of the product. Subculture was diluted, samples were filled in glass "growth flasks", instantly incubated and periodically removed so as to perform the viable count measurement in the course of the experiment. Experiments

327 were carried out in duplicate. The thermal program was monitored with the refrigerated and 328 heating circulator (FP40-HE, Julabo Labortechnik GmbH, Germany). At each sampling time, 329 1-mL aliquots were aseptically removed from each "growth flask", serially diluted in tryptone 330 salt broth and plated on nutrient agar $(15 \mathrm{~g} / \mathrm{L})$ with a double layer. Petri dishes were incubated 331 at $37^{\circ} \mathrm{C}$ for $24 \mathrm{~h}$ and colonies were counted.

332 3.4. Validation and assessment of the quality of the overall model 
Model accuracy was assessed by the estimation of confidence bands of predictions by using

334 the bootstrap percentile method (Efron and Tibshirani, 1993). Forty six growth kinetics were 335 performed in nutrient broth at 11 constant temperatures ranging from $10{ }^{\circ} \mathrm{C}$ to $46{ }^{\circ} \mathrm{C}$ (data not 336 shown). Bootstrap of each kinetic was made in order to take the experimental errors of 337 kinetics into account. The appropriate residuals of each kinetic were drawn with replacement. 338 Twenty five thousands bootstrap set of primary parameters were obtained. Each set of 339 bootstrapped $\mu_{\max }$ values were used to fit the secondary model. Then bootstrapped values of 340 parameters $T_{\min }, T_{\mathrm{opt}}$ and $\mu_{\text {opt }}$ were used to predict the bacterial growth with the overall model.

341 Secondary observed residuals were drawn with replacement and added to the $\mu$ predicted 342 value. Primary residuals were added to the predicted kinetics to consider the experimental 343 error of cell number estimation. Twenty five thousands bootstrapped growth kinetics were 344 obtained for each validation experiment and sorted in ascending order at each calculation 345 time. The quartiles $2.5 \%$ and $97.5 \%$ of the sorted bootstrapped kinetics were taken to give the 346 inferior and superior limits. These points were linked to give an approximation of the 95 347 percent confidence bands of the predicted growth kinetics. To validate the assumptions made 348 and the model, less than $5 \%$ of the points must fall outside the confidence bands.

349 With regard to the assessment of the quality of the overall model predictions various 350 statistical criteria were calculated at all the tested conditions of validation experiments. 351 Correlation coefficients $(R)$ between observations and predictions were calculated using the 352 'corrcoef' function of MATLAB 6.5. The correlation coefficient is related to the covariance $353 \operatorname{cov}$ by:

$$
R(i, j)=\frac{\operatorname{cov}(i, j)}{\sqrt{\operatorname{cov}(i, i) \operatorname{cov}(j, j)}}
$$

355 where $i$ is the observations index and $j$ is the variables index. 
356 Bias factor $B_{f}$ (Eq. (18)) and Accuracy factor $A_{f}$ (Eq. (19)) were calculated as proposed by 357 Jeyamkondan et al. (2001). These factors were initially introduced by Ross (1996) but here, 358 the predicted values are normalized.

$$
\begin{aligned}
& B_{f}=10^{\sum \log (P / O) / n} \\
& A_{f}=10^{\sum \log (P / O) / n}
\end{aligned}
$$

where $O$ and $P$ are observed and predicted microbial populations in $\log _{10} \mathrm{CFU} / \mathrm{mL}$ and $n$ is

362 the number of observations. The bias factor indicates the relative average deviation of predicted and observed bacterial growth. However it has to be kept in mind that this deviation does not directly concern the size of the population, but its logarithmic transformation which reduces the effect of outliers.

A bias factor of 1 indicates perfect agreement between observed and predicted values. However, $B_{f}>1$ or $<1$ indicates that the model predicts $N$ upper than or lower than observed values. For example, $B_{f}=1.1$ means that predictions are on average upper than observed values by $10 \%$. The accuracy factor gives indication of the spread of the results about the predicted value. An accuracy factor of 1 represents perfect agreement between observed and predicted values. This parameter quantifies the difference between observed and predicted values. For example, $A_{f}=1.25$ indicates that the average deviation of the predicted values

373 from the observed values is $25 \%$. It has to be kept in mind that this deviation does not directly concern the size of the population, but its logarithmic transformation.

\section{Results}

\subsection{Model validation at constant air temperature and changing convective heat transfer}

\section{7 coefficient}

\subsubsection{Growth simulation}

Thermal programs tested at the validation stage were utilized at five different combinations of 
$\left(T_{\infty}\right)($ Fig. 2).

382 The obtained cooling profiles and growth predictions are presented in Fig. 3. As a rule, 383 bacterial growth kinetics were faster at the product centre than at its surface. In cases of 384 lowest thickness, simulated computing profiles (1c and 2c) were practically identical leading 385 to the same bacterial growth predictions ( $1 \mathrm{~g}$ and $2 \mathrm{~g}$ ) at the centre and at the surface of the 386 product. In fact, in these two experiments the product thickness was sufficiently low to 387 prevent a clear observation of an internal temperature gradient and the internal heat resistance 388 may had been neglected. In contrast, the difference between simulated theoretical temperature 389 kinetics at the centre and the surface of the product were more marked in the cases of the 390 highest thickness leading to an important thermal gradient within the product ( $3 \mathrm{c}$ and $4 \mathrm{c})$. For 391 that matter, the most important differences between internal and surface growth kinetics were 392 obtained in these two cases ( $3 \mathrm{~g}$ and $4 \mathrm{~g}$ ), particularly in the case of low heat transfer 393 coefficient.

394 On the other hand, additional simulated growth curves at constant temperatures equal to $T_{\infty}$ 395 were presented in Fig. 3. The aim of these further experiments was to compare the bacterial 396 growth that really occurs when temperature dynamic changes at the centre and at the surface 397 of the cooled product are considered, with the growth that would occur if external and internal 398 resistances were neglected.

\section{4.1.2. Validation results}

400 Each validation experiment regarding each $\left(T_{\infty}, h, E\right)$ combination (Fig. 2) was conducted 401 under two different refrigeration programs which corresponded to the simulated cooling of the 402 surface and the centre of the infinite slab-shaped product yielding a total of eight validation 403 tests. These tests lasted 24 hours with an initial temperature $T_{0}$ of $30{ }^{\circ} \mathrm{C}$. In order to validate 404 the overall mathematical model, Fig. 4 depicts predicted and observed E. coli SOR 201 405 growth during the simulated cooling at the centre or the surface of the product for the five 
cases presented in Fig. 2. A fair agreement between predicted and observed growth can be noted, and the observed growth data of E. coli SOR 201 were found to be adequately predicted by the overall mathematical model. For each predicted growth kinetic, 95 percent confidence bands calculated with bootstrap method are also presented in Fig. 4. All the 410 experimental data fell inside the confidence bands showing that the overall model was 411 successfully validated at the tested conditions.

412 On the other hand, the quality of the overall model prediction was assessed by the calculation 413 of correlation coefficient, $B_{f}$ and $A_{f}$ (see Table 3). The correlation coefficients were higher 414 than 0.975 showing that the bacterial growth was satisfactorily predicted by the overall 415 model. At all the instances, bias factors ranged from 0.98 to 1.00 indicating that en average, 416 the observed growth was at the most $2 \%$ higher than the predicted growth and that the overall 417 predictions agreed well with observed data with a slight under-prediction tendency by the model. In all the tested conditions, the percentage of predicted values which were different from Af values ranging from 1.01 to 1.05 .

421 Agreement between model predictions and experimental validation results was also assessed 422 by plotting predicted bacterial growth versus observed bacterial growth (Fig. 5). A perfect agreement between predicted and measured growth was observed for $30.80 \%$ of experimental data. A percentage of $25.36 \%$ of the observed-predicted values' pairs were laying under the 425 line of equivalence while $43.84 \%$ were laying above the line of equivalence.

4.2. Model validation at changing air temperature and constant convective heat transfer coefficient

\subsubsection{Growth simulation}

Fig. 6 illustrates the simulated thermal profiles and bacterial growth kinetics according to the conditions presented in Table 2 and $\$ 3.3$. Thermal and bacterial growth simulation results 
431 showed important differences of temperature profiles and growth between the product centre,

432 the product surface and the ambient air. During heating, the highest bacterial growth was

433 observed when simulations were carried out at air temperature, followed by the product's

434 surface and then by the product's centre. Conversely, an opposite trend was observed during

435 cooling. From a safety point of view, neglecting heat transfer phenomena that occur inside the

436 product and between the ambient air and the product is more dangerous at cooling stages than

437 at heating stages. Nevertheless this hazard depends on the temperature and duration history of

438 the cooling/heating stages. Consequently it's very important to take into account the actual

439 temperature of the product surface or centre rather than the ambient air temperature for a

440 reliable bacterial growth prediction.

$441 \quad$ 4.2.2. Validation results

442 Validation results regarding the three tested ambient scenarios are presented in figures 7 and

443 8. The observed growth data of $E$. coli SOR 201 were found to be adequately predicted by the

444 overall mathematical model. On the other hand, less than $5 \%$ of the experimental data fell

445 outside the 95 percent confidence bands showing that the overall model was successfully

446 validated at the tested conditions. Table 4 presents the statistical criteria related to the data of

447 validation at changing air temperature and shows correlation coefficients higher than 0.944 at

448 all the tested conditions. Bias factors obtained at all the assays were higher than 1 showing a

449 slight over-prediction tendency by the model. $A_{f}$ values (lower than 1.13 at all the instances)

450 indicate that the overall predictions agreed well with observed data. Fig. 8 shows predicted

451 bacterial growth versus observed bacterial growth and confirms that the overall model was

452 successfully validated, with a slight over-prediction tendency, for the tested dynamic 453 refrigeration cycles.

454 5. Discussion 
455 Traditionally, when simulating a bacterial growth during a product cooling or heating, 456 predictive microbiology took only the ambient air temperature into account, ignoring delays 457 and temperature gradients due to external and internal thermal resistances linked to the effects 458 of the medium thickness and of the convective heat transfer coefficient on the rate of heat 459 transfer. All the studies cited in Table 1 have evaluated the prediction of bacterial growth 460 under dynamic temperature conditions taking into account only the temperature of the 461 cooling/heating medium. Assuming that the bacterial growth directly occurs at the temperature of air is not valid. In fact, the local temperature at any given position in the product depends upon both $T_{\infty}$ and $h$. In the present study, predictive microbiology was 464 combined with heat transfer phenomena in order to develop an overall mathematical model 465 describing the effect of the ambient temperature and the convective heat transfer coefficient 466 on bacterial growth. The proposed method in this work is different than those in previous studies which combined predictive microbiology and heat transfer (Alavi et al., 2001; Amezquita et al., 2005; Bellara et al., 2000; Corradini et al., 2006). An experimental method was implemented in order to validate the model results. Thermal profiles were firstly 470 simulated at the centre and at the surface of the infinite slab shaped product. Then, 471 experiments were conducted under a changing temperature program corresponding to the 472 simulated temperature kinetics. The validation of the overall model was performed by the 473 comparison of the measured bacterial growths with model predictions at constant ambient air 474 temperature and changing convective heat transfer coefficient and product thickness (five 475 different combinations of product thickness, convective heat transfer coefficient and cooling 476 air temperature were tested), then at changing ambient air temperature and fixed convective 477 heat transfer coefficient and product thickness (three different ambient air scenarios assuming 478 alternated cooling and heating stages, drawn from real refrigerated food processes, were 479 tested). 
As expected, the results of the computer simulation related to single cooling stage experiments showed that the bacterial growth kinetics were faster at the product centre than at its surface. Moreover, the importance of the impact of the convective heat transfer coefficient and of the product thickness on the bacterial growth during the cooling of an infinite slab shaped product by pulsed air was pointed out. As an example, at the product half thickness, the level of bacterial growth accomplished after 5 hours of cooling with $h=8 \mathrm{~W} /\left(\mathrm{m}^{2} . \mathrm{K}\right)$ (case 3) was the same after 16.5 hours with $h=60 \mathrm{~W} /\left(\mathrm{m}^{2} . \mathrm{K}\right)$ (case 4). For these cases the product thickness was the same and the cooling air temperature was in case $34^{\circ} \mathrm{C}$ lower than in case 4. Similarly, at product half thickness, the cooling time needed to reach a same bacterial growth with low or high product thickness $(1 \mathrm{~cm}$ in case 2 and $6 \mathrm{~cm}$ in case 4$)$ was estimated to 17.5 hours and 8 hours, respectively, for the same convection level $\left(60 \mathrm{~W} /\left(\mathrm{m}^{2} . \mathrm{K}\right)\right)$. The 491 slowest simulated bacterial growth was observed with intermediate product thickness and convective heat transfer coefficient (case 5). Moreover, it obviously appears that the validity of the assumption of an instantaneously thermal equilibrium between the product and the cooling medium with regard to bacterial growth is depending on the level of convection. In fact, predicted growth kinetics at the surface of the product were close to those predicted at $T_{\infty}$ for high heat transfer coefficients $(h)$ equal to $60 \mathrm{~W} /\left(\mathrm{m}^{2} . \mathrm{K}\right)$, which corresponds to a strong air fan (Fig. 3: $2 \mathrm{~g}$ and 4g). At this instance, neglecting the external heat resistance may be accepted particularly for low product thickness $(1 \mathrm{~cm})$ where there's no internal heat resistance too. Oppositely, for low heat transfer coefficients $(h)$ equal to $8 \mathrm{~W} /\left(\mathrm{m}^{2} . \mathrm{K}\right)$, which 500 corresponds to the absence of fan, (Fig. 3: $1 \mathrm{~g}$ and 3g) important dissimilarities between 501 predicted growth kinetics at the surface of the product and at $T_{\infty}$ may be observed. Indeed, 502 assuming no external heat transfer resistance is not valid especially for high product thickness 503 of $6 \mathrm{~cm}$ (Fig. 3: 3g) where the bacterial growth that occurs when the product is cooled from $T_{0}$ 
difference of $1.35 \log _{10}(\mathrm{CFU} / \mathrm{mL})$ between the bacterial populations at the product surface and at $T_{\infty}$ was reached after 24 hours of growth. Besides, using the bootstrap percentile

507 method for the estimation of confidence bands of predictions, the model was successfully 508 validated at all the tested conditions.

509 Concerning the results related to alternated cooling and heating stage experiments, the model 510 was successfully validated at more complicated ambient air scenarios and lower inoculation 511 levels by plate count measurement method. These results showed that, in predictive 512 microbiology, assuming an instantaneously thermal equilibrium between the product and the 513 ambient medium is not valid and may have large consequences on risk assessment of 514 refrigerated food processes (see Fig. 9).

515 To assess the quality of the overall model, predicted bacterial growth was compared to 516 observed growth according to several statistical criteria related to the data of validation. Our 517 results pointed out a good agreement between predicted and observed growth.

518 On the other hand, in the overall model, as a primary bacterial model, a simple exponential 519 growth without lag time was assumed. In other words, it is supposed that the bacterial growth 520 occurred without delay when the product temperature was continuously changing. Our 521 assumption is in agreement with several previous studies. Although the fact that organisms 522 need to adapt to the new temperature, so that they go through a lag phase caused by the stress 523 of the temperature shift, was largely noticed in literature (Amezquita et al., 2005; Baranyi et 524 al., 1995; Koutsoumanis, 2001; Zwietering et al., 1994), the lag phase duration was rarely 525 considered in predictive models. In accordance with our work, no further delay occurring after 526 temperature shifts, once a cell population is growing exponentially, was frequently assumed 527 (Baranyi et al., 1995; Bovill et al., 2000; Koutsoumanis et al., 2006). Although, Swinnen et al. 528 (2005) demonstrated that temperature shifts crossing a lag/no lag transition zone (positioned 529 more or less between 22.78 and $23.86^{\circ} \mathrm{C}$ for E. coli $\mathrm{K} 12 \mathrm{MG} 1655$ ) will cause an intermediate 
530 lag phase, we consider that neglecting contingent intermediate lag phase by our model may be 531 a valid approach. In fact, simulated thermal profiles at product surface or centre due to heat 532 transfer phenomena (see Fig. 3 and Fig. 6) progressively changed with time and cannot be 533 regarded as instantaneous temperature shifts with given amplitude which may generate 534 intermediate lag phases.

535 Paradoxically, the complexity of foods' shapes and the lack of knowledge about their physical 536 properties dictate the utilization of simple model. We took as an example the case of infinite 537 slab, but the model can be generalised to complex shapes. A classical and relevant approach is 538 of course, the implementation of numerical modelling. Another approach is related to the 539 well-known Ball method (Ball, 1923) with its two empirical parameters, for heat treatment 540 processes calculations. Because foodstuffs shapes are complex and because their thermal 541 properties are often unknown, it can be relevant to implement a simple model including only 542 two parameters ( $j$ and $k$ of Eq. (1)) which can be easily empirically estimated from a simple 543 temperature registration and a simple linear regression of the reduced temperature (which is 544 linearised from a logarithmic transformation). Note that errors which can be generated by 545 "simplistic" heat transfer models are minor compared to errors which are linked to the 546 "biological background". Moreover, the overall model can be used for any bacterial strain 547 having known growth parameters $T_{m i n}, T_{o p t}$ and $\mu_{\text {opt }}$. Accordingly, the proposed model can be 548 used for designing safe cooling or heating processes and may be considered as a very useful 549 tool for risk assessment regarding food safety and process optimisation. 


\section{Appendix}

551 Equation of the the infinite series given by Carslaw and Jaeger (1986):

552

$$
\frac{T_{\infty}-T}{T_{\infty}-T_{0}}=\sum_{1}^{\infty} \frac{2 \sin \varphi_{n}}{\varphi_{n}+\sin \varphi_{n} \cos \varphi_{n}} \cos \left(\varphi_{n} \frac{x}{x_{\max }}\right) \exp \left(-\varphi_{n}{ }^{2} F o\right)
$$

553 with $x_{\max }$ is half-thickness for an infinite slab and $\varphi_{n}$ are the roots of the equation $\cot \varphi=\frac{\varphi}{B i}$.
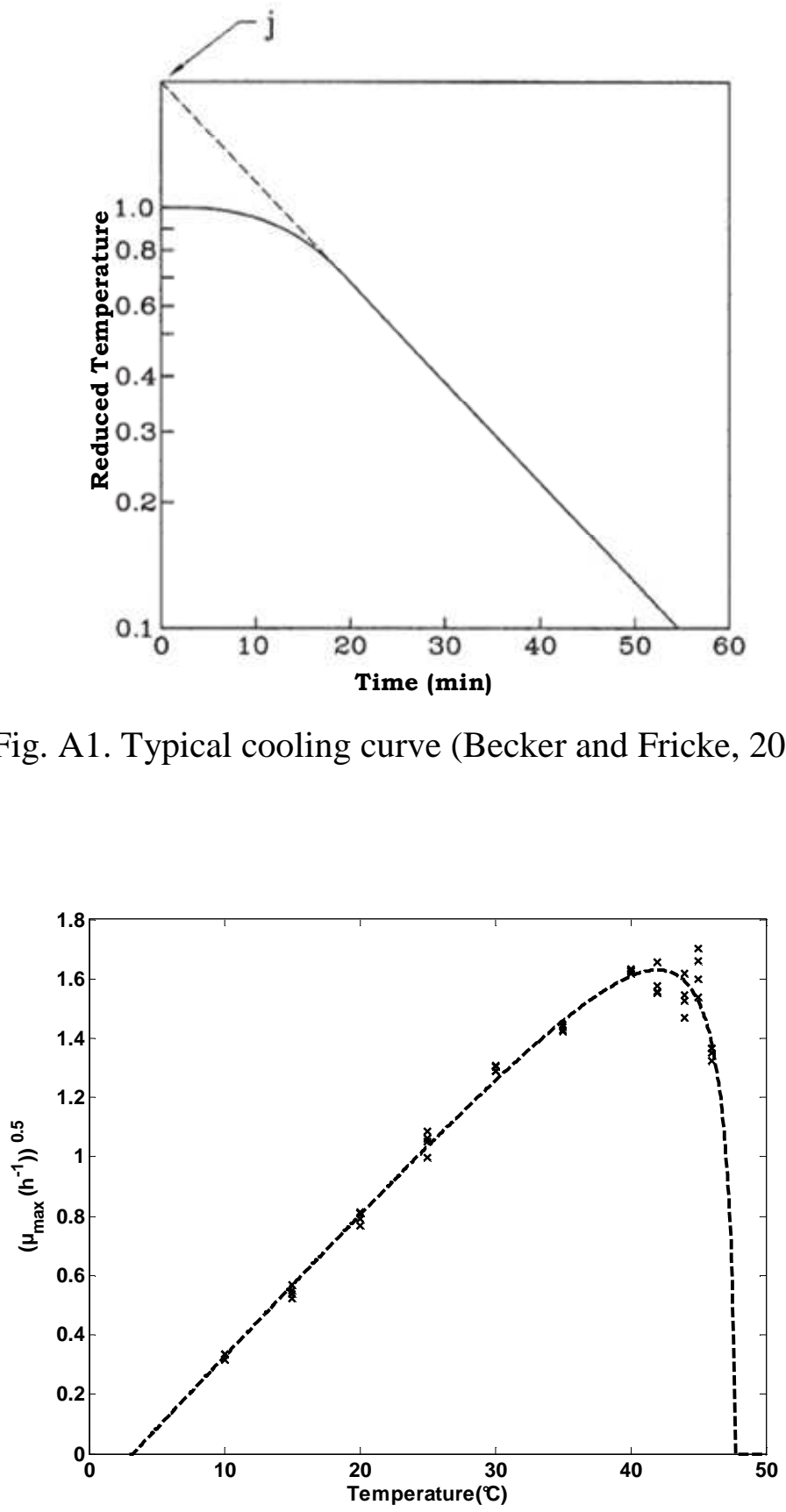

558 Fig. A2. Fit of the cardinal model on $\mu_{\max }$ values measured in nutrient broth $(\times)$. The dashed line denotes the fitted model on the experimental data. 
Alavi, S.H., Puri, V.M., Mohtar, R.H. 2001. A model for predicting the growth of

Listeria monocytogenes in packaged whole milk. Journal of Food Process Engineering 24, $231-251$.

Amezquita, A., Weller, C.L., Wang, L., Thippareddi, H., Burson, D.E. 2005.

Development of an integrated model for heat transfer and dynamic growth of Clostridium

perfringens during the cooling of cooked boneless ham. International Journal of Food Microbiology 101, 123-144.

Armitage, N.H. 1997. Use of predictive microbiology in meat hygiene regulatory activity. International Journal of Food Microbiology 36, 103-109.

Ball, C. 1923. Thermal process times for canned foods. Bulletin 7-1, 37 (National Research Council, Washington, DC).

Baranyi, J., Roberts, T.A. 1994. A dynamic approach to predicting bacterial growth in food. International Journal of Food Microbiology 23, 277-294.

Baranyi, J., Robinson, T.P., Kaloti, A., Mackey, B.M. 1995. Predicting growth of Brochothrix thermosphacta at changing temperature. International Journal of Food Microbiology 27, 61-75.

Becker, B.R., Fricke, B.A. 2004. Heat transfer coefficients for forced-air cooling and freezing of selected foods. International Journal of Refrigeration 27, 540-551.

Bellara, S.R., McFarlane, C.M., Thomas, C.R., Fryer, P.J. 2000. The growth of 581 Escherichia coli in a food simulant during conduction cooling: combining engineering and 582 microbiological modelling. Chemical Engineering Science 55, 6085-6095. 
Ben Amara, S., Laguerre, O., Flick, D. 2004. Experimental study of convective heat transfer during cooling with low air velocity in a stack of objects. International Journal of Thermal Sciences 43, 1213-1221.

Bimbenet, J.J., Duquenoy, A., Trystram, G. 2002. Génie des procédés alimentaires. Des bases aux applications. Dunod ed., Paris, France.

Bovill, R., Bew, J., Cook, N., D’Agostino, M., Wilkinson, N., Baranyi, J. 2000.

Predictions of growth for Listeria monocytogenes and Salmonella during fluctuating temperature. International Journal of Food Microbiology 59, 157-165.

Bovill, R.A., Bew, J., Baranyi, J. 2001. Measurements and predictions of growth for

Listeria monocytogenes and Salmonella during fluctuating temperature II. Rapidly changing temperatures. International Journal of Food Microbiology 67, 131-137.

Caro-Corrales, J., Cronin, K., Abodayeh, K., Gutiérrez-López, G., Ordorica-Falomir, C. 595 2002. Analysis of random variability in biscuit cooling. Journal of Food Engineering 54, 147156.

Carslaw, H.S., Jaeger, J.C. 1986. Conduction of Heat in Solids. $2^{\text {nd }}$ ed. Oxford 598 University Press.

Corradini, M.G., Amézquita, A., Normand, M.D., Peleg, M. 2006. Modeling and predicting non-isothermal microbial growth using general purpose software. International Journal of Food Microbiology 106, 223-228.

Dalgaard, P. 1995. Modelling of microbial activity and prediction of shelf life for packed fresh fish. International Journal of Food Microbiology 26, 305-317. de Jong, A.E.I., Beumer, R.R., Zwietering, M.H. 2005. Modeling growth of Clostridium perfringens in pea soup during cooling. Risk Analysis: An International Journal 25, 61-73. freezing of slab products. Journal of Food Engineering 30, 417-423. 
Efron, B., Tibshirani, R.J. 1993. Confidence intervals based on bootstrap percentiles. In:

609 An introduction to the Bootstrap. Chapman and Hall, New York, pp. 168-177.

Erdogdu, F. 2005. Mathematical approaches for use of analytical solutions in

611 experimental determination of heat and mass transfer parameters. Journal of Food 612 Engineering 68, 233-238.

613 Francois, K., Devlieghere, F., Standaert, A.R., Geeraerd, A.H., Cools, I., Van Impe, 614 J.F., Debevere, J. 2005. Environmental factors influencing the relationship between optical 615 density and cell count for Listeria monocytogenes. Journal of Applied Microbiology 99, 15036161515.

Fujikawa, H., Kai, A., Morozumi, S. 2004. A new logistic model for Escherichia coli 618 growth at constant and dynamic temperatures. Food Microbiology 21, 501-509.

619 Gibson, A.M., Bratchell, N., Roberts, T.A. 1987. The effect of sodium chloride and 620 temperature on the rate and extent of growth of Clostridium botulinum type A in pasteurized 621 pork slurry. Journal of Applied Bacteriology 62, 479-490.

622 Gill, C.O., Harrison, J.C.L. 1985. Evaluation of the hygienic efficiency of offal cooling 623 procedures. Food Microbiology 2, 63-69.

624 Gumudavelli, V., Subbiah, J., Thippareddi, H., Velugoti, P.R., Froning, G. 2007. 625 Dynamic predictive model for growth of Salmonella Enteritidis in egg yolk. Journal of Food 626 Science 72, M254-M262.

627 Huang, L. 2003. Dynamic computer simulation of Clostridium perfringens growth in 628 cooked ground beef. International Journal of Food Microbiology 87, 217-227.

629 Jeyamkondan, S., Jayas, D.S., Holley, R.A. 2001. Microbial growth modelling with 630 artificial neural networks. International Journal of Food Microbiology 64, 343-354.

631 Juarez Tomas, M.S., Bru, E., Wiese, B., de Ruiz Holgado, A.A.P., Nader-Macias, M.E. 632 2002. Influence of $\mathrm{pH}$, temperature and culture media on the growth and bacteriocin 
633 production by vaginal Lactobacillus salivarius CRL 1328. Journal of Applied Microbiology $63493,714-724$.

635 Juneja, V.K., Marks, H., Thippareddi, H. 2008. Predictive model for growth of 636 Clostridium perfringens during cooling of cooked uncured beef. Food Microbiology 25, 4263755.

638 Kondjoyan, A. 2006. A review on surface heat and mass transfer coefficients during air 639 chilling and storage of food products. International Journal of Refrigeration 29, 863-875.

640 Koseki, S., Isobe, S. 2005. Prediction of pathogen growth on iceberg lettuce under real 641 temperature history during distribution from farm to table. International Journal of Food 642 Microbiology 104, 239-248.

643 Koutsoumanis, K. 2001. Predictive modeling of the shelf life of fish under 644 nonisothermal conditions. Applied and Environmental Microbiology 67, 1821-1829.

645 Koutsoumanis, K., Stamatiou, A., Skandamis, P., Nychas, G.J.E. 2006. Development of 646 a microbial model for the combined effect of temperature and $\mathrm{pH}$ on spoilage of ground meat, 647 and validation of the model under dynamic temperature conditions. Applied and 648 Environmental Microbiology 72, 124-134.

649 Lebert, I., Lebert, A. 2006. Quantitative prediction of microbial behaviour during food 650 processing using an integrated modelling approach: a review. International Journal of 651 Refrigeration 29, 968-984.

652 Mafart, P. 1997. Génie industriel Alimentaire. Tome 1: Les procédés physiques de 653 conservation. Lavoisier Techniques \& Documentations ed., Paris, France.

654 Mafart, P. 2005. Food engineering and predictive microbiology: on the necessity to 655 combine biological and physical kinetics. International Journal of Food Microbiology 100, $656 \quad 239-251$. 
658 Presser, K., Ratkowsky, D.A., Ross, T., Salter, M., Soontranon, S. 1997. Quantitative 659 Microbiology: A Basis for Food Safety. Emerging Infectious Diseases 3, 541-550. McMeekin, T.A., Olley, J.N., Ross, T., Ratkowsky, D.A. 1993. Predictive 661 Microbiology: theory and application Research Studies Press, Taunton, Somerset, England. Ratkowsky, D.A., Olley, J., McMeekin, T.A., Ball, A. 1982. Relationship between temperature and growth rate of bacterial cultures. Journal of Bacteriology 149, 1-5. Ross, T. 1996. Indices for performance evaluation of predictive models in food microbiology. Journal of Applied Bacteriology 81, 501-508.

Rosso, L., Lobry, J.R., Bajard, S., Flandrois, J.P. 1995. Convenient model to describe 667 the combined effects of temperature and $\mathrm{pH}$ on microbial growth. Applied and Environmental Microbiology Vol. 61, p. 610-616. microbial lag phenomena due to a sudden rise in temperature: a systematic macroscopic study. International Journal of Food Microbiology 100, 85.

U.S.D.A. 1999. Performance standards for the production of certain meat and poultry products. Final rule. Federal Register 64, 732-749. Microbiology 57, 1094-1101. 204-213. 
683 system for prediction of the microbial spoilage in foods. Journal of Food Protection 55, 973684979.

685

686 
Fig. 1.

690

691 Calibration curve between viable counts and absorbance data depicted with solid line. 692 Experimental data measured at $30^{\circ} \mathrm{C}$ in nutrient broth are marked with (o).

693

694 Fig. 2.

695

696 Experimental design implemented for the validation of the overall model at different 697 combinations (mentioned with numbers from 1 to 5) of product thickness $(E)$, convective heat 698 transfer coefficient $(h)$ and refrigeration temperature $\left(T_{\infty}\right)$.

699

Fig. 3.

701

Cooling scenarios (from $1 \mathrm{c}$ to $5 \mathrm{c}$ ) and bacterial growth curves (from $1 \mathrm{~g}$ to $5 \mathrm{~g}$ ) obtained from simulation of the overall model at the five cases of the experimental design. Symbols in predicted cooling profiles: temperature of product centre (line --) and temperature of product surface (line - - - ). Symbols in predicted growth curves: bacterial growth at product centre (line - - ), bacterial growth at product surface (line - - - ) and bacterial growth that occurs at $T_{\infty}($ line ......).

Fig. 4.

711 Comparison of predicted and observed Escherichia coli SOR 201 growth during cooling. $\boldsymbol{a}$ :

712 case 1 at the centre or the surface of the product. $\boldsymbol{b}$ : case 2 at the centre or the surface of the 713 product. $\boldsymbol{c}$ : case 3 at the product centre. $\boldsymbol{d}$ : case 3 at the product surface. $\boldsymbol{e}$ : case 4 at the product 714 centre. $f$ : case 4 at the product surface. $g$ : case 5 at the product centre. $\boldsymbol{h}$ : case 5 at the product surface. Symbols in experimental data: $0, \square, \Delta$. Predicted growth curves estimated by the overall model are presented with (line -). 95 percent confidence bands obtained with bootstrap method are presented with (line - -). 
Fig. 5.

Predicted bacterial growth from the overall model versus observed bacterial growth obtained with constant air temperature. Symbols: $\square$ (case 1), o (case 2). Symbols related to product surface experiments: $*$ (case 3 ), $\Delta$ (case 4$), \diamond$ (case 5). Symbols related to product centre experiments: • (case 3), + (case 4), x (case 5). The line of equivalence between predicted and observed growth is marked with (line - ).

Fig. 6.

Thermal profiles (from 1c to 3c) and bacterial growth curves (from $1 \mathrm{~g}$ to $3 \mathrm{~g}$ ) obtained by simulation of the overall model at the three ambient air scenarios. Symbols in predicted cooling profiles: temperature of product centre (line - ) and temperature of product surface (line - - - . Symbols in predicted growth curves: bacterial growth at product centre (line

$734-$ ), bacterial growth at product surface (line - - - ) and bacterial growth that occurs at $T_{\infty}$ (line ......).

Fig. 7.

Comparison of predicted and observed Escherichia coli SOR 201 growth during thermal processing at changing air temperature. $\boldsymbol{a}, \boldsymbol{c}$ and $\boldsymbol{e}$ depict the model validation results at the product centre according to cycle $\mathrm{N}^{\circ} 1$, cycle $\mathrm{N}^{\circ} 2$ and cycle $\mathrm{N}^{\circ} 3$, respectively. $\boldsymbol{b}, \boldsymbol{d}$ and $\boldsymbol{f}$ depict the model validation results at the product surface according to cycle $\mathrm{N}^{\circ} 1$, cycle $\mathrm{N}^{\circ} 2$ and cycle $\mathrm{N}^{\circ}$, respectively. Symbols in experimental data: 0 , $\square$. Predicted growth curves estimated by the overall model are presented with (line -). 95 percent confidence bands obtained with bootstrap method are presented with (line --).

Fig. 8.

748 Predicted bacterial growth from the overall model versus observed bacterial growth obtained

749 with changing air temperature. Symbols related to product surface experiments: $\square$ (Cycle

$\left.750 \quad \mathrm{~N}^{\circ} 1\right), *\left(\right.$ Cycle $\left.\mathrm{N}^{\circ} 2\right), \Delta\left(\right.$ Cycle $\left.\mathrm{N}^{\circ} 3\right)$. Symbols related to product centre experiments: o (Cycle $\left.751 \quad \mathrm{~N}^{\circ} 1\right), \cdot\left(\right.$ Cycle $\left.\mathrm{N}^{\circ} 2\right),+\left(\right.$ Cycle $\left.\mathrm{N}^{\circ} 3\right)$. The line of equivalence between predicted and observed growth is marked with (line - ). 
753 Fig. 9.

754 Comparison of the bacterial growth prediction at ambient temperature according to cycle $\mathrm{N}^{\circ} 1$

755 with the model validation results at product's centre $(\boldsymbol{a})$ and at product's surface $(\boldsymbol{b})$. Symbols

756 in experimental data: $\mathrm{o}, \square$. Symbols in predicted growth curves: bacterial growth at product's

757 surface or centre (line - ), bacterial growth that occurs at $T_{\infty}$ (line .....). 95 percent confidence

758 band of predictions at $T_{\infty}$ obtained with bootstrap method is presented with (line -- ). 


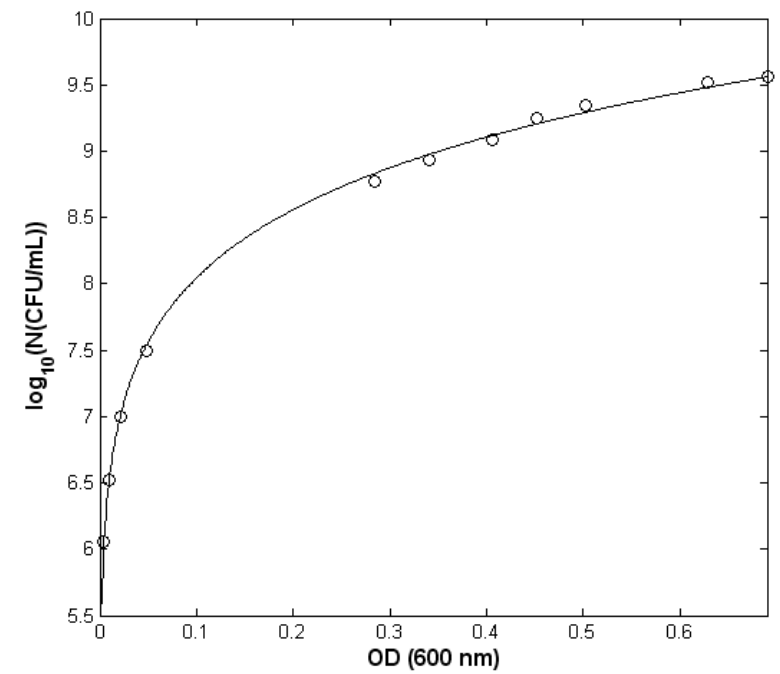

762

763 Fig. 1. 
764

765

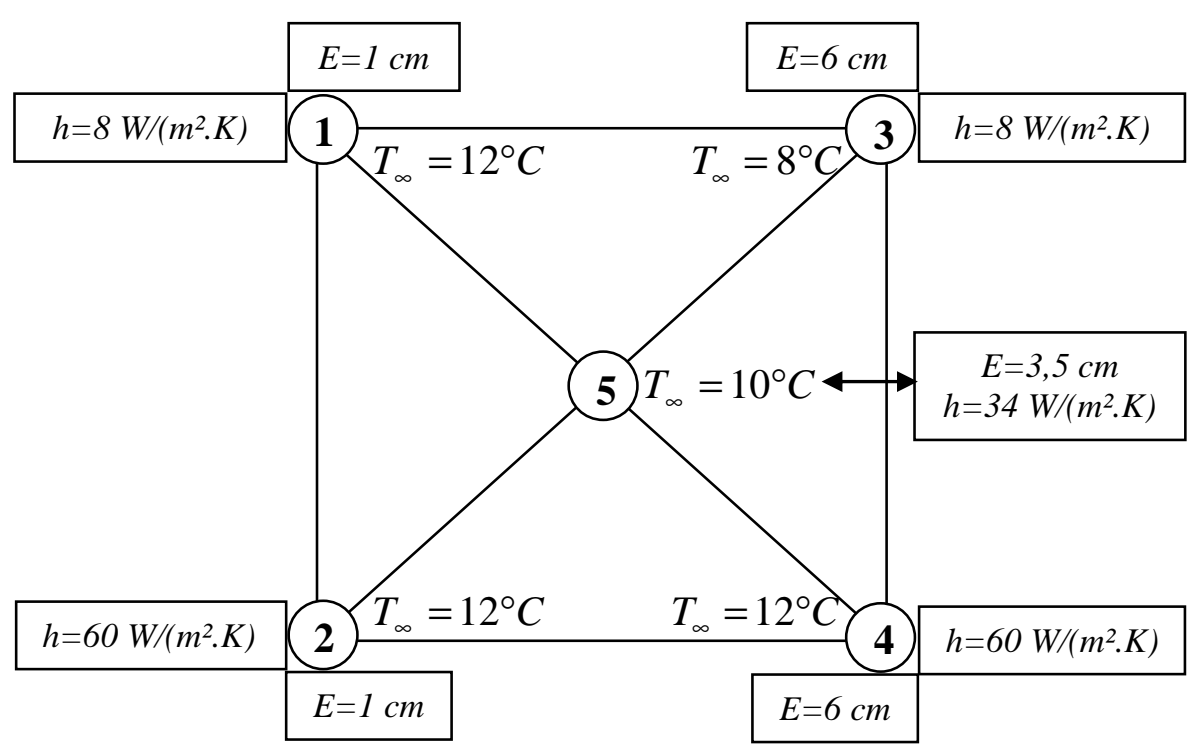

766

767 Fig. 2.

768

769

770

771

772

773

774

775

776

777

778

779

780

781

782 

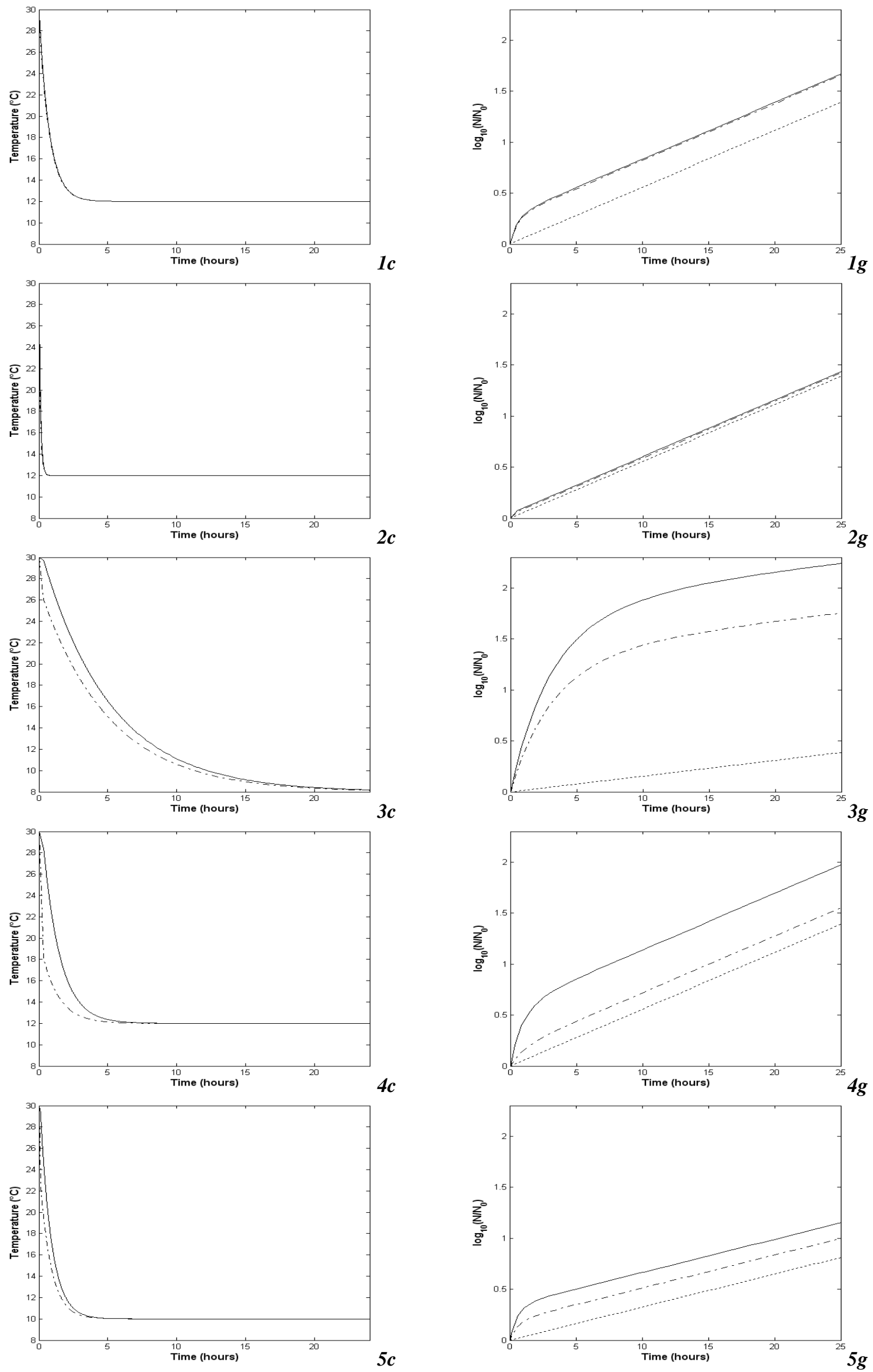

783 Fig. 3. 

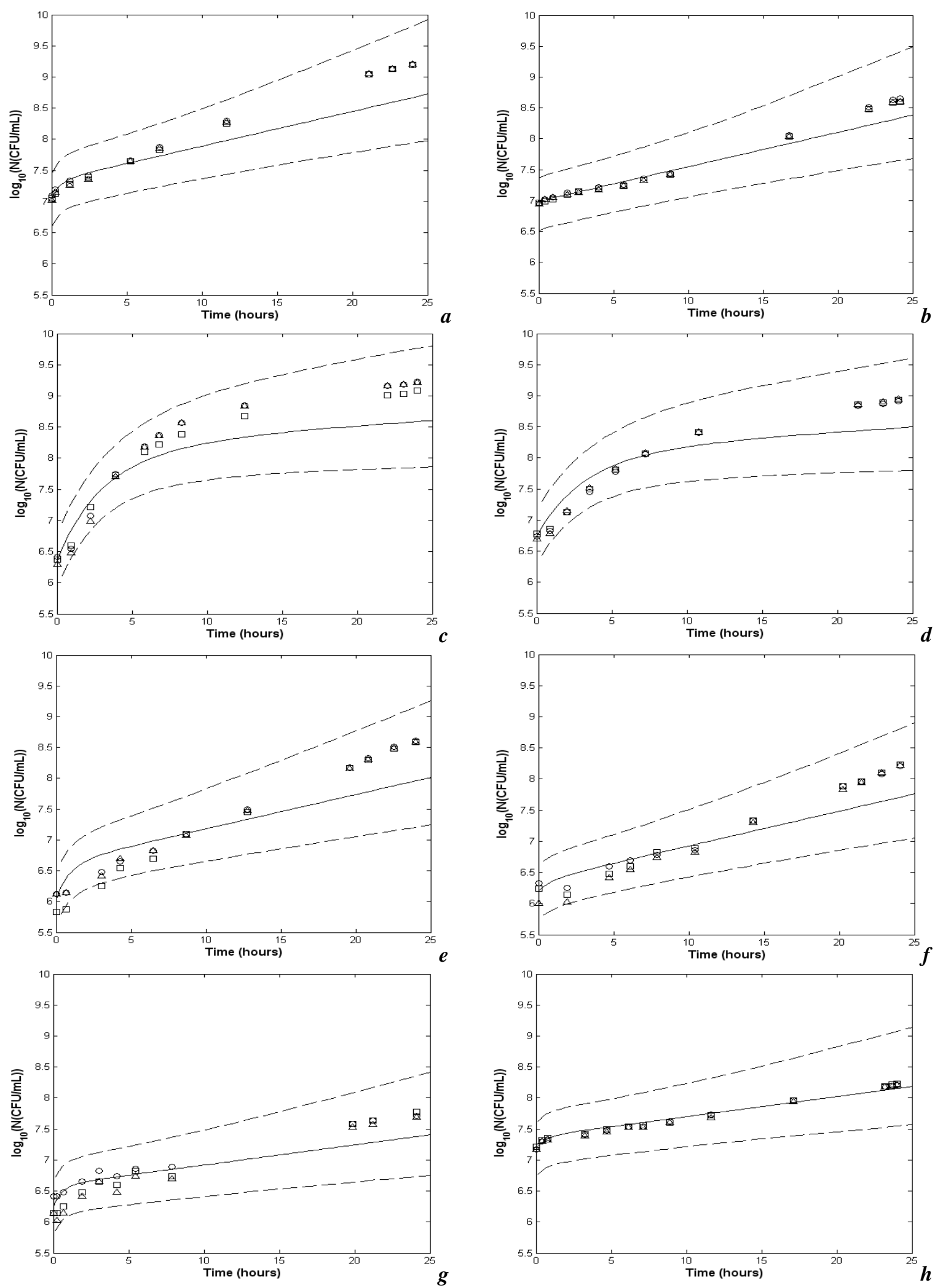

$785 \quad$ Fig. 4. 


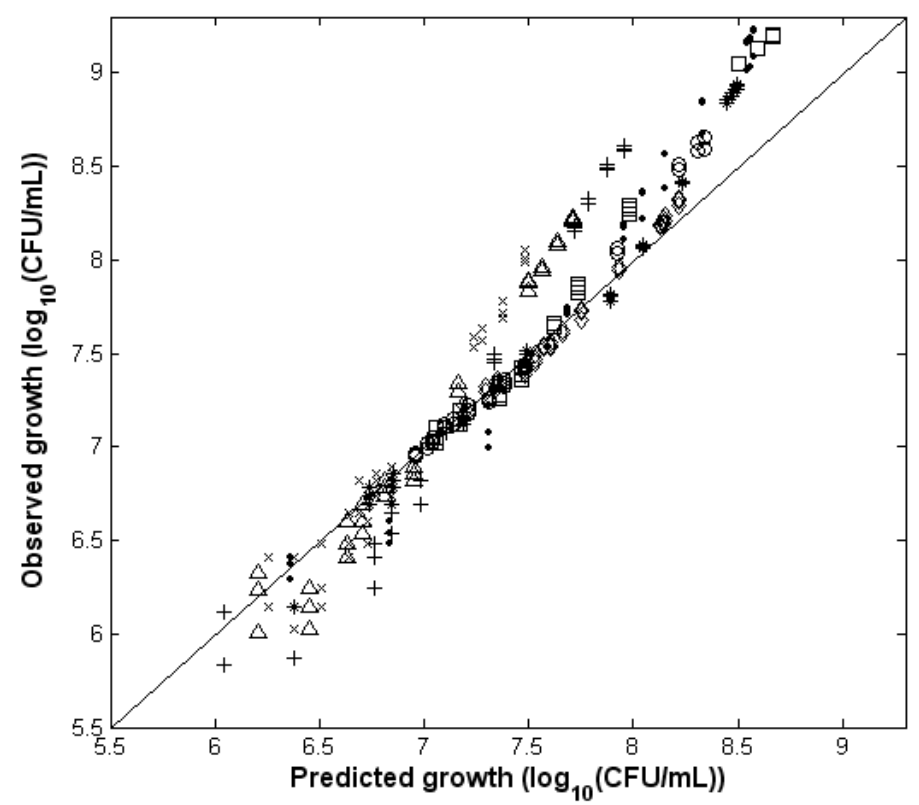

$790 \quad$ Fig. 5.

791 

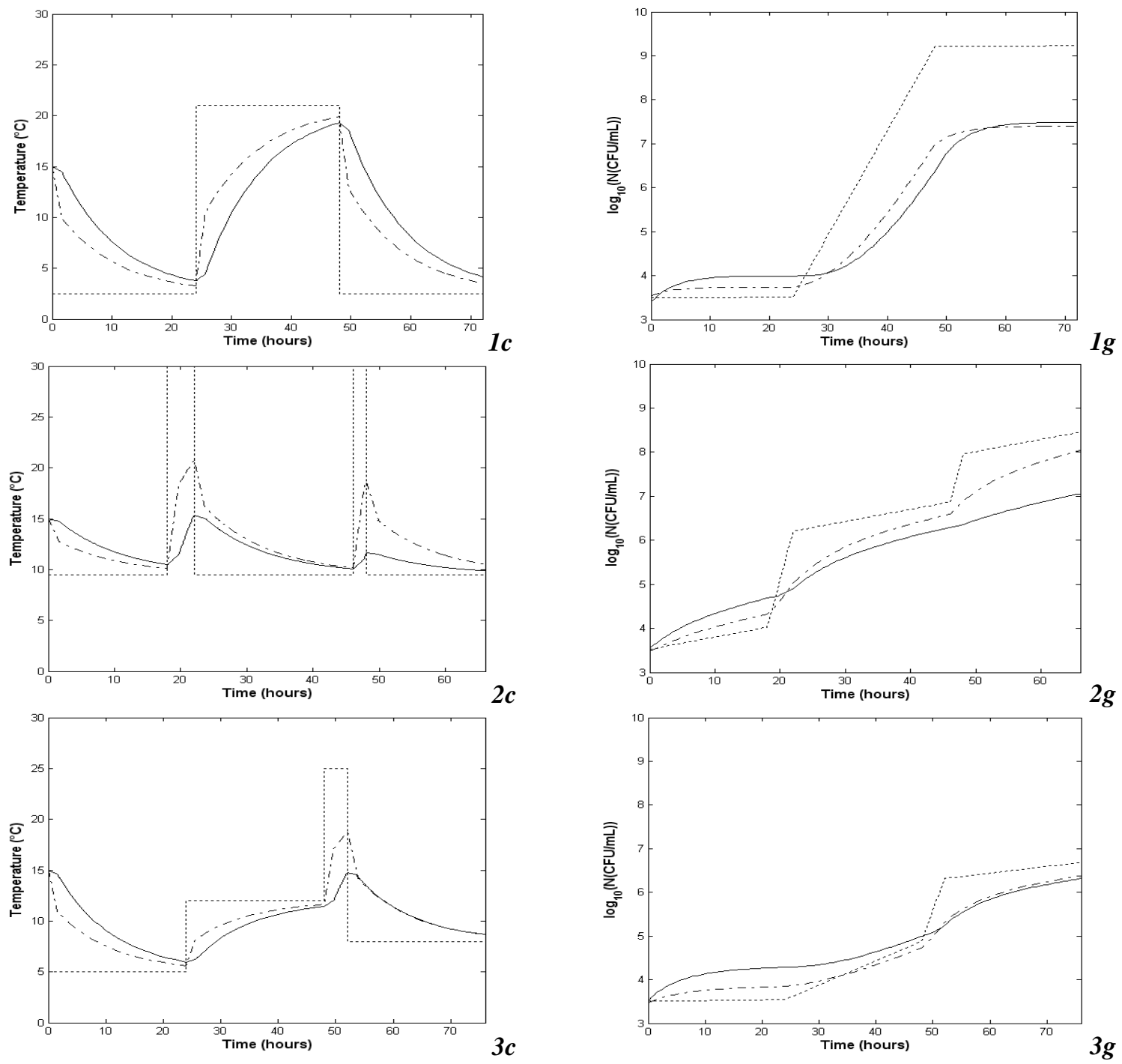

793 Fig. 6. 
794
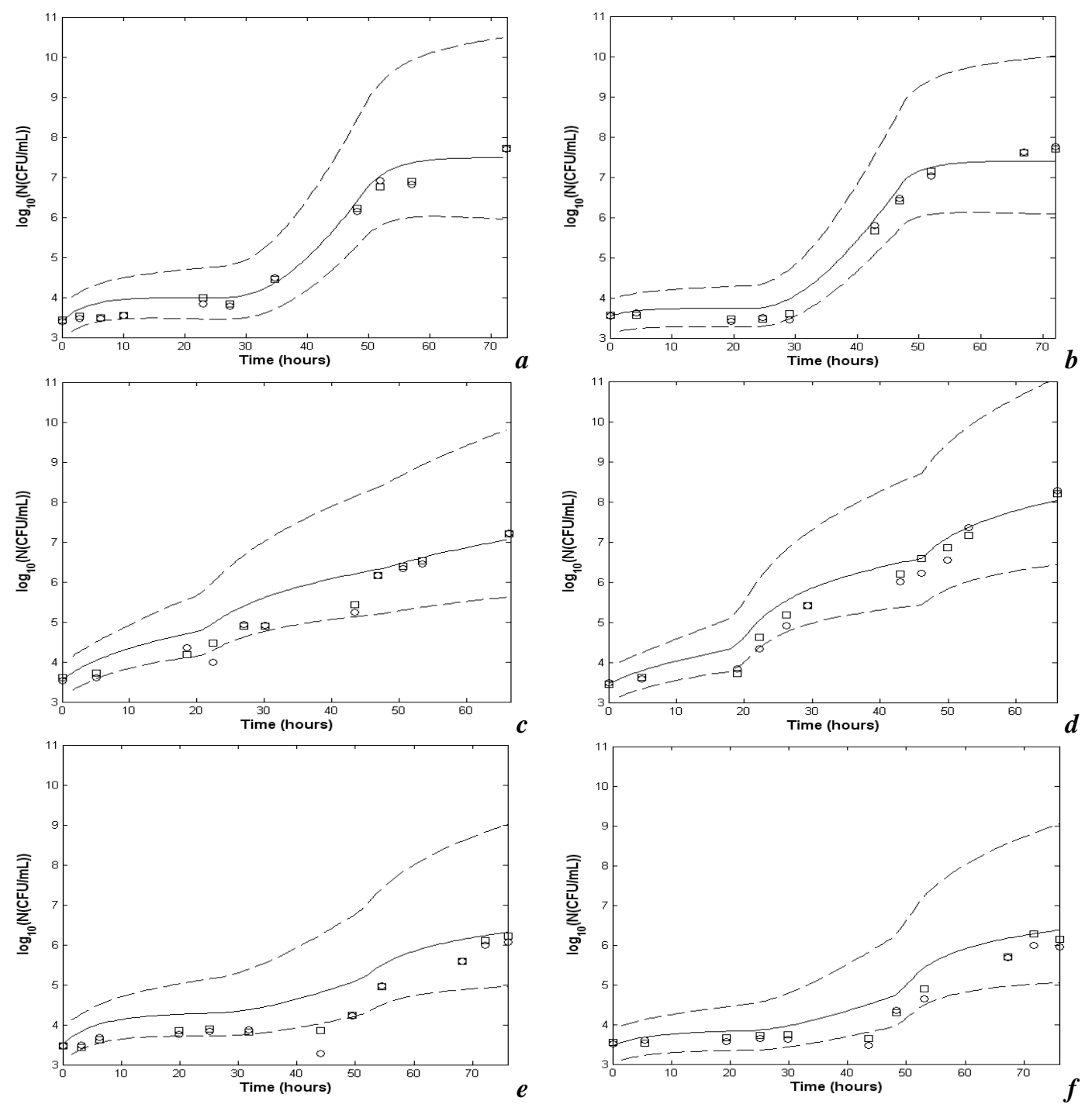

795 Fig. 7. 


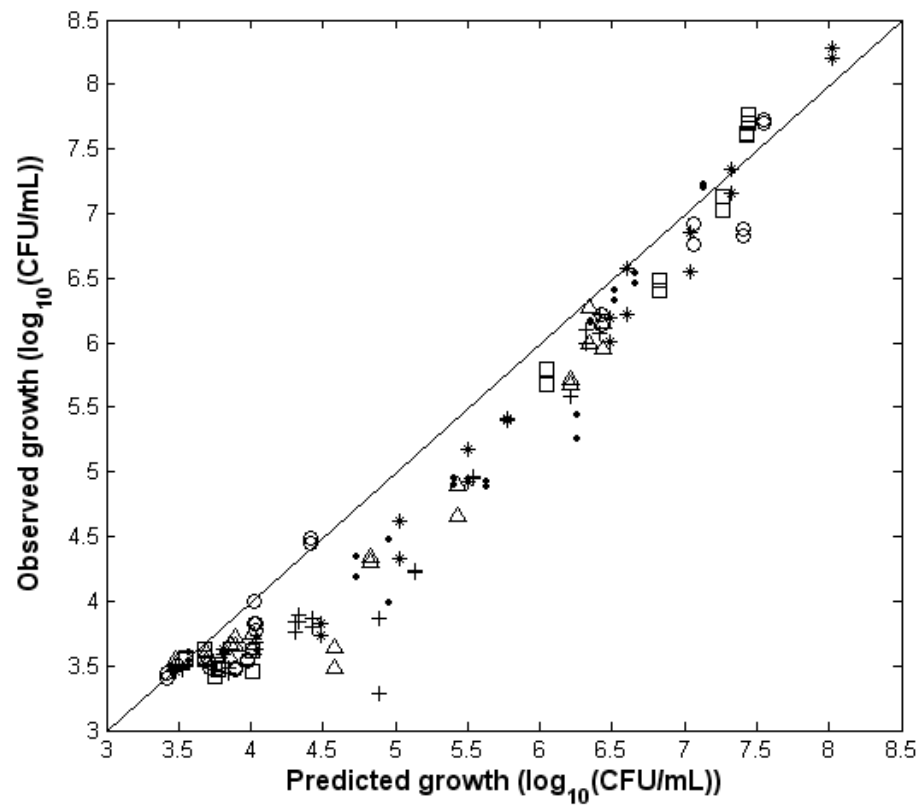

797 Fig. 8. 

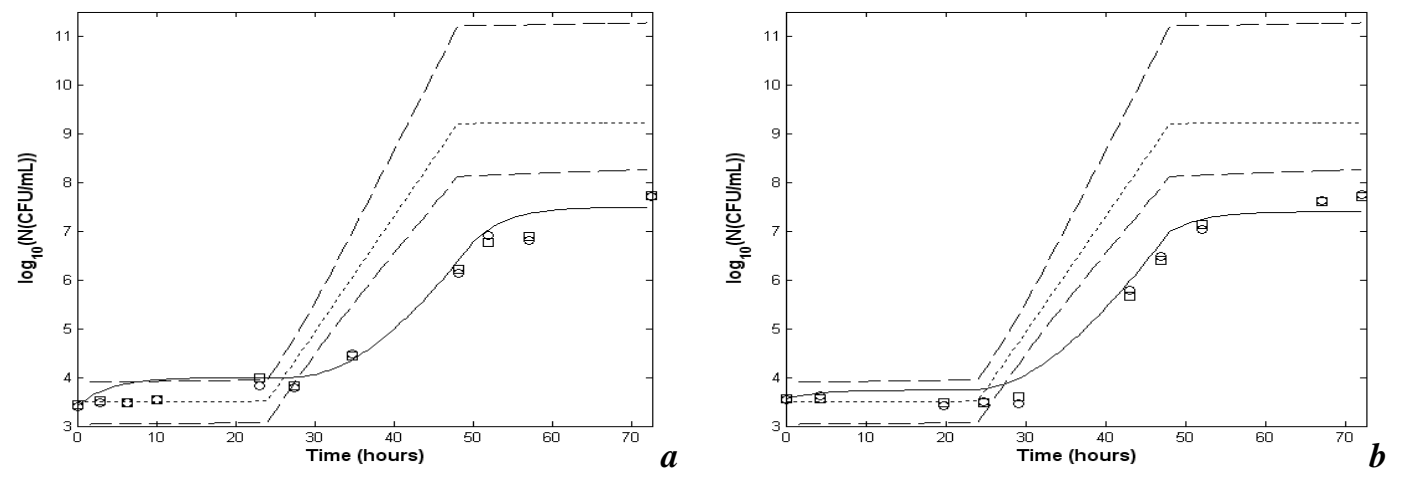

799

800

801 Fig. 9.

802 
804 List of previous works dealing with models predicting the bacterial growth under dynamic

805 temperature conditions

806

Model Secondary model $\quad$ Solution method $\quad$ Validation conditions

ad Roberts Quadratic polynomial Numerical solution by the aranyi and model.

4). fourth order Runge-Kutta method.

Rates of change of $\mathrm{T}$ ranging from Bovil $1.7^{\circ} \mathrm{C} . \mathrm{h}^{-1}$ to a virtually instantaneous change: cooling from $25^{\circ} \mathrm{C}$ to $-2,2,5$ or $10^{\circ} \mathrm{C}$ and heating from $2^{\circ} \mathrm{C}$ to $25^{\circ} \mathrm{C}$.

istic model. Arrhenius equation.

Various types of a dynamic temperature history with various intervals were studied for of Escherichia coli 1952 growth prediction.

Growth of Salmonella Enteritidis in egg yolk under varying temperature profiles (exponential and linear cooling, exponential heating and sinusoidal temperatures). cooked ground beef under fluctuating temperature conditions between $30^{\circ} \mathrm{C}$ and $45^{\circ} \mathrm{C}$ (square waved) and under continuous temperature changes from $51^{\circ} \mathrm{C}$ to $10^{\circ} \mathrm{C}$ (linear and exponential cooling).
Numerical solution by the fourth order Runge-Kutta method.

Numerical solution by the fourth order Runge-Kutta method.
Growth of Clostridium perfringens in ourth order Runge-Kutta method. 
808 Tested temperature scenarios for the validation of the model at changing air temperature and

809 constant convective heat transfer coefficient equals to $8 \mathrm{~W} /\left(\mathrm{m}^{2} . \mathrm{K}\right)$

810

Stage of the cycle Temperature $\left({ }^{\circ} \mathrm{C}\right)$ Duration $(\mathrm{h})$ Cycle $\mathrm{N}^{\circ} 1$

Storage in a cold room 2.5

Refrigeration stopped due to an accidental failure of the installation 21 24

Repaired breakdown and remaining product in the cold room 2.5 24

Cycle $\mathrm{N}^{\circ} 2$

Industrial storage and transport

9.5
24

Household doorstep delivery

Storage in refrigerator 30 9.5 18

Product on the table 30

Remaining product in the refrigerator

9.5

Cycle $\mathrm{N}^{\circ} 3$

Storage and transport

Storage in the refrigerated cabinet 9.5 2

Household doorstep delivery

Storage in refrigerator

5

12

24

12

25

24

8

4
24 
$811 \quad$ Table 3

812 Statistical criteria related to the data of validation at constant air temperature and changing

813 convective heat transfer coefficient

814

\begin{tabular}{cccc}
\hline Test conditions & $R$ & $B_{f}$ & $A_{f}$ \\
\hline Case 1 & 0.996 & 0.98 & 1.03 \\
$\quad$ Case 2 & 0.996 & 0.99 & 1.01 \\
$\quad$ Case 3 & 0.987 & 0.98 & 1.04 \\
$\begin{array}{c}\text { at product centre } \\
\text { Case 3 }\end{array}$ & 0.987 & 0.99 & 1.02 \\
$\begin{array}{c}\text { at product surface } \\
\text { Case } 4\end{array}$ & 0.976 & 0.99 & 1.05 \\
$\begin{array}{c}\text { at product centre } \\
\text { Case } 4\end{array}$ & 0.986 & 0.99 & 1.03 \\
$\begin{array}{c}\text { at product surface } \\
\text { Case } 5\end{array}$ & 0.975 & 0.99 & 1.03 \\
$\begin{array}{c}\text { at product centre } \\
\text { Case 5 }\end{array}$ & 0.994 & 1 & 1.01 \\
at product surface & & & \\
\hline
\end{tabular}

815 
$817 \quad$ Table 4

818 Statistical criteria related to the data of validation at changing air temperature and constant 819 convective heat transfer coefficient equals to $8 \mathrm{~W} /\left(\mathrm{m}^{2} . \mathrm{K}\right)$

820

821

\begin{tabular}{cccc}
\hline Test conditions & $R$ & $B_{f}$ & $A_{f}$ \\
\hline $\begin{array}{c}\text { Cycle 1 } \\
\text { at product centre } \\
\text { Cycle 1 }\end{array}$ & 0.991 & 1.05 & 1.05 \\
$\begin{array}{c}\text { at product surface } \\
\text { Cycle 2 }\end{array}$ & 0.992 & 1.04 & 1.05 \\
$\begin{array}{c}\text { at product centre } \\
\quad \text { Cycle 2 }\end{array}$ & 0.963 & 1.08 & 1.08 \\
$\begin{array}{c}\text { at product surface } \\
\text { Cycle 3 }\end{array}$ & 0.986 & 1.06 & 1.06 \\
$\begin{array}{c}\text { at product centre } \\
\text { Cycle 3 }\end{array}$ & 0.944 & 1.13 & 1.13 \\
at product surface & 0.964 & 1.09 & 1.09 \\
\hline
\end{tabular}

822

823 